\title{
The Film Studies Dictionary
}

\author{
By Jan Uhde
}

Spring 2001 Issue of KINEMA

SEMANTIC VAGUENESS has been a typical feature of cinema's professional terminology and taxonomy, a problem which exists both in the academic circles of film studies and among film-makers themselves. Moreover, it is amplified by fashionable but meaningless jargon of some film reviewers and commercial newspeak, the intention of which is often disinformation in the first place.

Over the past decades, a few attempts have been made to improve this situation through the publication of film term glossaries and dictionaries, including Geduld-Gottesman's An Illustrated Glossary of Film Terms (1973), S. E. Browne's Film-Video Terms and Concepts (1992) and F. Beaver's Dictionary of Film Terms (1994). A major difficulty facing film dictionary writers has been whether to aim at the practical filmmaker or academic theorist; uniting these two user groups has not always been successful. Another problem plaguing some of these reference publications has been that the entries did not go beyond the most basic definitions.

A recent contribution to the film terminology labyrinth, the Film Studies Dictionary has succeeded where many of its predecessors have failed. Its three authors have made an effort to bridge the gap between the theoretical and the practical perspectives; they have set out to "balance the aesthetic and industrial" aspect, aiming their book both at the filmmaker, the film student and the culturally astute general reader. Included are generous explanations of many key terms to help the user better understand a question or problem. Some of the FS Dictionary's entries intelligently illuminate complex concepts in a nutshell and, with the attached essential bibliographical references, dispatch the reader into the right direction to satisfy his curiosity.

A competent typesetting design is a key to the success of a good reference book, especially that which deals with theoretical and abstract concepts. The FS Dictionary offers, without typographical gimmicks, a simple, intuitive and readable design which complements the content of the entries. The extensive cross-referencing allows the dictionary's user to move easily between related concepts -- an indispensable instrument to be appreciated in the epoch of the hypertext.

Compressing the terminology of extensive subjects such as film-making and film studies into a single volume of less than 300 pages is an almost impossible task and undoubtedly, the FS Dictionary's authors faced difficult choices. One of their decisions was not to include personal and national cinemas entries. These are brought up only when they are essential to specific concepts, trends or principles (such as Italian Neorealism). This approach seems to work successfully. On the other hand, some terms should have been included, for example "socio-comedy" (comedy of morals), an ample sub-genre in Italian cinema and other productions and "allegory," even though it may already be familiar to students of literature and drama. Also, "video CD" (or VCD, an audiovisual medium similar to DVD but using the lower-quality data compression of MPEG1) has been left out. Although virtually unknown in Europe and North America, it is probably the most popular home theatre format in Asia; China alone produces two million VCD players annually.

The concept of "off-screen space", though mentioned in the FS Dictionary (p.221), would deserve an independent entry as it is one of the most fertile aesthetic concepts of contemporary cinema; the contribution of Yasujiro Ozu in this regard should have been included too.

The absence of diacritics when quoting non-English or non-French names or titles (see the Czech new wave entry, p. 63) is startling. In a publication with evident ambitions to scholarly quality and accuracy, such matters should not be considered expendable.

Despite these minor shortcomings, the Film Studies Dictionary is an excellent and extremely valuable publication which is bound to be appreciated by film professionals, scholars and movie lovers who have been eagerly waiting for such a work.

This book is undoubtedly an important contribution to a more meaningful discussion and understanding of the two key aspects of cinema: film-making and film study. 


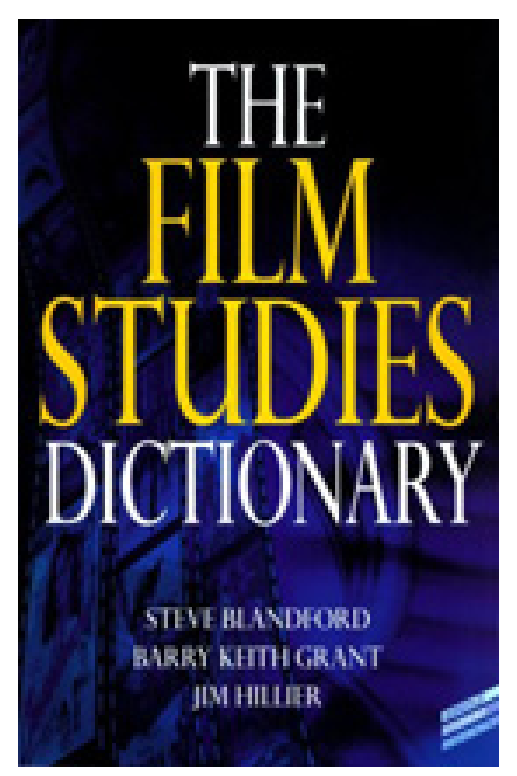

Figure 1: BY: Steve Blandford, Barry Keith Grant, Jim Hillier. I PUBLISHER: Arnold Publishers (London) and Oxford University Press (New York) I YEAR: 2001. I PAGES: 287pp. ๆ ISBN: 0-34074191-0 ๆ ISBN: 0-340-74190-2

\section{Author Information}

Jan UHDE is Professor Emer. (Film Studies) at the University of Waterloo, Ontario, Canada. Born in Brno, Czech Republic. Graduated (MA) from the Faculty of Arts, Masaryk University, Brno; PhD received at the University of Waterloo, Ontario, Canada. He taught at the University of Waterloo (1970-2012) where he founded a General and Honours BA program in Film Studies at the Department of Fine Arts.

Publications: Latent Images: Film in Singapore Second edition, with Yvonne Ng Uhde (Ridge Books, National University Press of Singapore, 2010); Latent Images: Film in Singapore, with Yvonne Ng Uhde (Oxford University Press, 2000); Latent Images: Film in Singapore CD-ROM (2003, co-author); Vision and Persistence: Twenty Years of the Ontario Film Institute (University of Waterloo Press, 1990) and Ontario Film Institute Programming Activities Index 1969-1989 (Toronto: Ontario Science Centre, 1990). He co-edited the Place in Space: Human Culture in Landscape (Proceedings from the Second International Conference of the Working Group "Culture and Landscape" of the International Association of Landscape Ecology, Pudoc Scientific Publishers, Wageningen, Holland, 1993). Jan Uhde has published articles and reviews in several countries (including Canada, USA, Germany, Italy), participated in international juries at film festivals and presented papers at international conferences in North America and Europe. In 1998/99, he was a visiting researcher at the School for Film and Media Studies, Ngee Ann Polytechnic, Singapore.

His professional and research interests focus on Singapore cinema; the identification and distancing mechanisms of the film viewer; the non-authored modifications and manipulation of films; and specific aspects of film history, including the Central European cinema.

He founded KINEMA in 1993. 